\title{
Recovery of A Native Tree Following Removal of An Invasive Competitor In The Context of Potential Endangered Bird Habitat
}

Alexander Goetz ( $\sim$ alexander.goetz23@du.edu )

University of Denver https://orcid.org/0000-0003-1834-3071

lan Moffit

University of Denver

Anna A. Sher

University of Denver

\section{Research Article}

Keywords: riparian restoration, invasive species, Tamarix, bird habitat, Southwestern willow flycatcher

Posted Date: July 29th, 2021

DOl: https://doi.org/10.21203/rs.3.rs-719797/v1

License: (c) (i) This work is licensed under a Creative Commons Attribution 4.0 International License.

Read Full License 


\section{Abstract}

Invasive species removal is a common focus in restoration ecology, but the ultimate goal of native plant species recovery and habitat recovery is often elusive. Control of invasive Tamarix spp. shrubs in the American Southwest has only sometimes led to increased native species cover; this is of particular concern for the protection of the endangered Southwestern willow flycatcher (Empidonax extimus trailii, abbr. SWFL) that nests readily in Tamarix when native Salix canopy is absent. If we can identify the conditions that lead to more native trees as well as habitat protection for the SWFL, we can prioritize restoration efforts more effectively and reduce conflict between conservation goals. To determine whether reduction in the invasive Tamarix led to more Salix cover (and thus no net loss in SWFL habitat), we compiled data on vegetation, soils, and geographic conditions in 260 sites where Tamarix had been subject to control efforts and 132 positive and negative reference sites. We found that (1) reduction in Tamarix only increased Salix cover in wetter sites, and was greater when a particular, low-disturbance removal method was used; however the increase did not typically compensate for the overall losses in canopy cover, and (2) Salix cover was generally highest in locations with low drought stress, as reflected by soil properties, distance to water, and climate. These results suggest that the presence and recovery of Salix is dependent on its relatively narrow environmental niche, in contrast with Tamarix's broader one. Thus, although abundance of Salix and Tamarix was negatively correlated, this is likely because of Salix's different niche, as much as or more than direct interspecific competition. Our findings demonstrate that removal of an invasive species does not necessarily lead to reestablishment of the native species they appeared to displace. We suggest that in the case of promoting habitat for SWFL and other birds, outcomes of restoration activity can be improved by focusing Tamarix removal efforts on sites more likely to promote Salix growth based on environmental characteristics.

\section{Introduction}

Invasive species removal is a common goal of ecological restoration as biological invasions are known to be major threats to ecosystem stability and biodiversity, particularly affecting threatened species (Vitousek et al. 1996, 2008; Dueñas et al. 2018). However, previous research has shown mixed outcomes of invasive species removal in terms of whole-ecosystem benefits (Shafroth et al. 2005; Kettenring and Adams 2011; González et al. 2015; Monaco et al. 2017). Removal efforts may fail and/or have unintended consequences and may actually cause more damage than the invasive species itself, due to insufficient understanding of ecosystem processes or an overly narrow spatio-temporal focus (Kettenring and Adams 2011).

A possible negative consequence of invasive species removal is the loss of functionally important characteristics of the invader that facilitate other native species. Facilitation of native species by an invader has been observed in an increasing number of cases across ecosystems (Van Riel and Jordaens 2000; Rodriguez 2006; Essl et al. 2017). In particular, it is possible for an invasive species to functionally replace a lost native species by providing an ecological resource. As biological invasions are associated with loss of native biodiversity, a consequential loss of ecosystem functions provided by natives is 
expected (Rodriguez 2006). Examples of habitat functional replacement by an invader include endemic land snails of North Atlantic islands relying on several exotic plants for habitat (Van Riel and Jordaens 2000) and exotic blackberry in Australia providing habitat for several small mammals where native understory is no longer present (Packer et al. 2016). Several examples are seen across ecosystems with native birds specifically utilizing invasive vegetation for habitat (Zavaleta et al. 2001; Ceia et al. 2011; Ma et al. 2014; Rodríguez et al. 2015; Moyka 2016). In cases where the native species that uses the invasive species is endangered or otherwise a focus for conservation, there can be conflict between restoring native habitat and protecting a native species which would be harmed by removal of the invader.

A particularly controversial case of novel habitat interaction occurs following removal of the invasive shrub Tamarix spp. along riparian corridors in the American Southwest. Tamarix spp. has the capacity to create large monocultures that exclude native trees, change the soil chemistry and biota, and increase wildfire risk, among other ecosystem changes (Sher and Quigley 2013). The Southwestern willow flycatcher (Empidonax extimus trailii, abbr. SWFL) is an endangered migratory bird that has historically nested in dense willow stands (Salix spp.) but now will nest in stands of Tamarix as the abundance of Salix has declined (Zavaleta et al. 2001; Hatten 2016; Raynor et al. 2017). Removal of Tamarix has been a management priority for decades, but in more recent years there has been controversy surrounding the associated loss of potential nesting habitat for SWFL (Sher 2013). This concern has been particularly due to the use of the tamarisk leaf beetle (Diorhabda spp.) as a biological control agent, as its spread into SWFL ranges cannot be controlled (Bean and Dudley 2018). In response, a series of lawsuits forced an end to continuing biocontrol releases, but existing populations continue to expand (Bean and Dudley 2018). As a result, SWFL habitat continues to be threatened by the biocontrol agent. Understanding the impact of invasive species removal on native flora and fauna is an important goal, particularly in this system where there is conflict between conservation of an endangered species and restoration of the overall ecosystem.

Previous research has shown that Tamarix removal has had variable impact on native vegetation cover (e.g., González et al. 2017a, Sher et al. 2018), however, only one has considered replacement by Salix trees specifically (González et al. 2020), and to our knowledge no one has previously quantified the response of Salix to Tamarix removal. Even though interspecific competition is unlikely to have been the mechanism of initial invasion (Sher and Marshall 2003), mature Tamarix trees effectively block light and otherwise can suppress neighboring vegetation (Ostoja et al. 2014). Thus, the removal of Tamarix has the potential to promote native growth due to competitive release. However this does not always occur; theories as to why include negative effects on native species of highly-disturbing Tamarix removal methods on native plants, competition from secondary invasions, and/or unfavorable abiotic conditions. For Salix, a hydrophilic species, we might expect that recovery after removal of Tamarix would only occur if there is enough water at the site to support Salix. We might also expect that method of Tamarix removal would matter, given previous findings on native species more generally (González et al. 2017a, Sher et al. 2018). 
Some studies have shown that it is possible to reestablish SWFL populations through active planting of Salix following Tamarix removal (Newell et al. 2003; Ahlers and Moore 2009), However, plantings are often known to fail (González et al. 2018). Furthermore, most Tamarix removal relies on passive revegetation (González et al. 2017). Thus, understanding the conditions under which recovery is possible can allow for more effective targeting of restoration efforts in the context of SWFL conservation. Tamarix has a broader ecological niche than the Salix species present in the study extent, so while Tamarix can competitively exclude Salix, it is not known whether Salix will be able to regenerate in formerly Tamarixdominated sites (Hultine and Dudley 2013; Nagler and Glenn 2013; Ohrtman and Lair 2013). If we can identify conditions leading to more native vegetation cover as well as habitat protection for the SWFL, we can prioritize efforts more effectively and reduce conflict between conservation goals.

In general, we are interested in whether there will be SWFL habitat, in the form of Salix cover, in locations where Tamarix is removed. To this end, we ask the following questions: 1) Does Salix cover increase proportionally with reduction in Tamarix cover, and does either the Tamarix removal method or hydraulic conditions affect this response? 2) What other site conditions are associated with the greatest recovery of Salix in removal sites, and what site conditions are generally associated with high Salix cover? By examining post-restoration dynamics of a novel ecosystem at a large scale, we can determine how environmental and anthropogenic factors affect recovery trajectories and, in turn, provision of habitat for an endangered species.

\section{Methods}

We compiled data on vegetation response to Tamarix removal and associated environmental variables from three published studies with sites that were distributed across the Upper Colorado, Lower Colorado, and Rio Grande river basins in the southwestern US (González et al. 2017a, b; Sher et al. 2018; Fig. 1). These sites covered a range of abiotic environmental conditions as well as biotic starting points (González et al. 2017a). In total, there were 260 sites where Tamarix had been subject to active removal and/or biocontrol and 132 reference sites. Removal treatments included all that are typical for this species, including biological control, prescribed burning, extraction or mulching with heavy machinery, chainsaw cutting (usually with herbicide applied to stumps afterwards to prevent resprouting; referred to as cut-stump), and biological control (Gonzalez et al. 2017b).

Independent variables in our analysis included both aspects of management and abiotic features measured at each site (González et al. 2017a, b; Sher et al. 2018; Table 1). "Site type" was our categorical variable used to explore the differences in response among the four removal methods and two categories of non-removal, reference sites. When more than one removal method was used, the one considered highest disturbance was used (González et al. 2017a). Of the 132 non-removal, reference sites, 53 were "desirable" (i.e., dominated by native vegetation; mean Tamarix cover $=0.84 \%$, maximum cover $=8.6 \%$ ) while 79 were "undesirable" (as deemed by managers due to Tamarix abundance, mean $=46.6 \%$; González et al. 2017a). Other data on the management of sites included whether herbicides (of any type for any purpose) were applied, and whether active introduction of desirable vegetation by planting or 
seeding was used. Details regarding herbicides or planting techniques/approaches were usually unavailable and so could not be included in the models. Environmental data available for these sites included information about climate, geography, hydrology, and soils (Table 1). Some variables in the source data had missing data for some rows; if more than $20 \%$ of data was missing, we excluded the variable from analysis, and if less than $20 \%$ was missing we filled in missing values with the row median. The variable "time since Tamarix removal" was not included both because it was not available for all sites, and it was highly non-significant for explaining Salix cover $\left(F_{1,198}=0.011, p=0.92\right)$.

Table 1: List of all explanatory variables included in analysis. 


\begin{tabular}{|l|}
\hline Management \& vegetation variables \\
\hline Change in Tamarix cover \\
\hline Tamarix cover before removal \\
\hline Site type (positive and negative references, restoration methods) \\
\hline Herbicide used at any point (including cut-stump treatment) \\
\hline Active introduction of native plants \\
\hline All-Salix/S. exigua cover before removal \\
\hline Climate variables \\
\hline Minimum average temperature (average of 30 years prior to removal date) \\
\hline Maximum average temperature \\
\hline Average precipitation \\
\hline Precipitation year sampling \\
\hline Minimum temperature year sampling \\
\hline Maximum temperature year sampling \\
\hline Geography variables \\
\hline Longitudinal slope \\
\hline Elevation above sea level \\
\hline Distance to nearest paved road or railway \\
\hline Distance to nearest unpaved or paved road/railway \\
\hline Hydrology variables \\
\hline Distance to river's edge \\
\hline River width \\
\hline Elevation above water level \\
\hline Soil variables \\
\hline Electrical conductivity \\
\hline pH \\
\hline Percent sand \\
\hline
\end{tabular}

For our dependent variables, we used two measures of Salix response to Tamarix removal treatments: change in cover over time and final year cover (i.e., final year of monitoring for a given site). By testing the 
response of both change and "final" measures of Salix cover, we were able to investigate the response of Salix both by 1) considering Salix response as a function of the efficacy of Tamarix control and 2) by using presence of Tamarix at a single point in time as a predictor. The latter is the more common approach used, but it only tells us whether there is a correlation between cover of the two tree species, which could be due to abiotic environmental factors, not competitive exclusion. Whereas the former analysis of change is a better test of the impact of removal (Sher et al. 2018).

Our first variable, "final" cover, represented the last time data was collected for each site $(n=392)$. Cover was a standardized measure of percent abundance, calculated for each plant species found at each site (González et al. 2017a); because SWFL can nest in any Salix species, we used the sum of cover for all Salix species (henceforth "all-Salix"; Table 1). We also separately examined Salix exigua (aka coyote willow; sandbar willow). S. exigua was the single most abundant Salix species across sites (Fig. 2) and also has several functional differences from other Salix species, including the ability to reproduce asexually via resprouting (Rood et al. 2011).

Change in cover (for both all-Salix and S. exigua) was calculated as the difference between the final year measurement and a control site measurement. Of the 392 total sites, 180 had "before-after" controls, with data for pre-and post-restoration conditions, and could thus be analyzed in terms of vegetation cover change over time (for more detail on this variable see Sher et al. 2020).

It is important to note that no SWFL populations were present at any of the sites used in this study; since the SWFL is a federally endangered bird, it would be illegal to remove Tamarix at a site known to support breeding populations. Thus, this study is assessing potential (not current) habitat, as well as Salix cover in general as an intrinsic restoration goal. The range of the SWFL overlaps some of our more southern study sites (specifically in southern Nevada, Arizona, and New Mexico; Hatten 2016), but its range is likely to eventually encompass all sites as the SWFL adapts to climate change. Many bird species have already shifted their ranges northward due to increasing temperatures (Spence and Tingley 2020). Thus, determining habitat for SWFL beyond the current breeding locations and range is important for understanding the ongoing effects of Tamarix removal.

\section{Statistical Analysis}

To answer our first question about whether there was evidence that Salix cover increased with decreasing Tamarix cover, we investigated Salix change over time as a function of Tamarix change over time with a linear mixed-effect model (LME; Zuur et al. 2009) using river reach as a random effect to account for spatial auto-correlation; this was done for each treatment type (biological control alone, cut-stump method, heavy machinery and burning, and both undesirable and desirable controls) separately (respectively $n=33,67,33,14,11,22)$ and combined $(n=180)$. To explore whether the Salix response to change in Tamarix cover was moisture-dependent, we then used we used linear mixed models with backward stepwise selection of the independent variables that included both main effects of Tamarix change over time, hydrological variables, and interactions between them, with river reach as random 
effect $(n=180)$. The backwards selection for all linear mixed models was done using Akaike's Information Criterion (AIC) to identify significant variables to be used in the final model.

To answer our second question regarding which variables best predicted change over time of Salix more generally, we used linear mixed models with backward stepwise selection to predict response of both allSalix and $S$. exigua cover using all independent variables, with river reach as a random effect $(n=180)$. Finally, we identified the conditions that predicted Salix and S. exigua cover regardless of whether Tamarix was removed or not, using all independent variables and all sites $(n=392)$. Our sample size was too small relative to the variance among sites to consider all possible interaction terms of our independent variables, so only interactions that tested our specific hypothesis about the role of water were analyzed, separately from these general explorations. In addition to exploring the interactions between change in Tamarix and hydrological variables, we also tested interactions between herbicide use and climate variables, because herbicide was selected in all change-over-time models but showed a high degree of variability.

Several of the environmental variables exhibited multicollinearity (Appendix A); elevation above sea level, average precipitation, and average minimum and maximum temperatures were all correlated predictors of climate. Likewise, distance of each site to a paved road was correlated with distance to any road and to the site's longitudinal slope. To address this issue, each model was first created using all independent variables with a maximum likelihood calculation, then stepwise selection using AIC. For change-over-time analyses we used the final-year values for all abiotic environmental variables, as they did not change significantly over the duration of the study (results not shown). The same methods were used for both the final-year and change over time models, but with some different starting variables due to differences in available data between final-year-only and change-over-time datasets (e.g., Tamarix change over time vs. Tamarix final cover as explanatory variables; Appendix C). See Appendix B for starting models: 21 for final cover models and 42 for change over time. There were more of the latter since we could build models with Tamarix cover before removal and alternatively with Tamarix cover change over time as explanatory variables, whereas the final cover models only had Tamarix cover before removal. Each explanatory variable was scaled (constrained to $(-1,1)$ ). Final mixed models were constructed using restricted maximum likelihood calculations. For each model we calculated conditional and marginal adjusted $\mathrm{R}^{2}$ and tested model significance using a log-likelihood test to compare with a null model with only the random factor (river reach) as an explanatory variable. Finally, in order to determine whether any variables significantly explained Salix cover variation on their own, we conducted univariate tests of each variable on final-year cover, using river reach as a random variable.

All analyses were performed using R version 3.3.6 with RStudio version 1.2.5042 using the functions "Ime" and "stepAIC" in the nlme package (Pinheiro et al. 2020).

\section{Results}


Question 1: Does Salix cover increase proportionally with reduction in Tamarix cover and does either the Tamarix removal method or hydraulic conditions affect this response?

Salix did increase as a function of Tamarix decrease, but only where there were indications of higher water availability. Both all-Salix and S. exigua cover change over time were explained by a significant interaction between Tamarix change over time and both average precipitation and river width; where precipitation or river width was higher, there was a proportional negative relationship between Tamarix and Salix cover change, but at lower precipitation or river width we saw a positive relationship between Tamarix and Salix cover change (Table 2). Sites near wider rivers showed a negative relationship between Salix and Tamarix cover change while sites near narrow rivers showed a positive relationship. In the case of river width however we saw more of a threshold effect where slopes were negative among all but the narrowest rivers. At the most water-stressed sites (very low river width and average precipitation) there was a high degree of variation in both Salix and Tamarix cover change, but the relationship was generally positive, suggesting that at this level of abiotic stress there was little interspecific competition occurring.

There was also an indication that removal method was important: all-Salix cover increased as Tamarix cover decreased when the low-disturbance method of cut-stump was used, though the relationship had a very low adjusted marginal $\mathrm{R}^{2}(0.058 ;$ Fig. 3$)$. We did not find any significant relationships $(p>.05)$ between $S$. exigua change over time and Tamarix overall or by removal method.

Table 2: Results of general linear mixed models from backwards stepwise selection using AIC, showing all-Salix and $S$. exigua cover change over time as a function of interactions between change in Tamarix and hydrological variables. For both models, river reach was included as a random variable. Significant variables at an alpha of 0.05 are bolded. Average precipitation refers to a 30 year mean for that location. 


\begin{tabular}{|c|c|c|c|c|c|}
\hline $\begin{array}{l}\text { Response } \\
\text { metric }\end{array}$ & Explanatory variable & Coefficient & $\begin{array}{l}\text { p-value } \\
\text { (indiv.) }\end{array}$ & $\begin{array}{l}\text { Adj. } \\
\text { marginal } \\
\mathrm{R}^{2} \text { (entire } \\
\text { model) }\end{array}$ & $\begin{array}{l}\text { p-value } \\
\text { (entire } \\
\text { model) }\end{array}$ \\
\hline \multirow[t]{6}{*}{$\begin{array}{l}\text { All-Salix change } \\
\text { over time }\end{array}$} & $\begin{array}{l}\text { Change in Tamarix cover * } \\
\text { river width }\end{array}$ & -3.339 & 0.192 & 0.354 & $<0.0001$ \\
\hline & $\begin{array}{l}\text { Change in Tamarix cover * } \\
\text { average precipitation }\end{array}$ & -5.047 & $<0.0001$ & & \\
\hline & Change in Tamarix cover & 0.569 & 0.255 & & \\
\hline & Soil electrical conductivity & -1.237 & 0.114 & & \\
\hline & Average precipitation & 0.899 & 0.170 & & \\
\hline & River width & 0.435 & 0.934 & & \\
\hline \multirow{5}{*}{$\begin{array}{l}\text { S. } \\
\text { exigua change } \\
\text { over time }\end{array}$} & $\begin{array}{l}\text { Change in Tamarix cover * } \\
\text { river width }\end{array}$ & -2.720 & 0.040 & 0.274 & 0.036 \\
\hline & $\begin{array}{l}\text { Change in Tamarix cover * } \\
\text { average precipitation }\end{array}$ & -4.469 & 0.002 & & \\
\hline & Change in Tamarix cover & 0.139 & 0.393 & & \\
\hline & River width & 0.521 & 0.926 & & \\
\hline & Average precipitation & 0.925 & 0.395 & & \\
\hline
\end{tabular}

Question 2a: What site conditions are associated with the greatest increase in cover of Salix in removal sites?

Stepwise selection on the change in Salix cover over time resulted in 5 distinct models, with similar adjusted $R^{2}$ values around 0.30 (Fig. 4A); for $S$. exigua change over time there were also 5 models, and adjusted $\mathrm{R}^{2}$ ranged from 0.52 to 0.56 (Fig. 4B). Site type (including Tamarix removal methods and the reference sites) was selected in only one model, generally showing the pattern of positive change for cut stump but highly variable for most site types and not significant in a univariate test (Appendix D). Notably, change in Tamarix cover was not selected as a significant explanatory variable in the Salix change in cover models.

Herbicide use was significant in all models, with more Salix and $S$. exigua cover increase over time where herbicide was used. However, for all-Salix species, herbicide use interacted with precipitation during the year sampled $(p=0.005, F=5.44)$; the positive effect of herbicides was greater where precipitation was higher. Site type (including Tamarix removal methods and the reference sites) was selected in only one model, generally showing the pattern of positive change for cut stump but highly variable for most site types and not significant in a univariate test (Appendix D). 
Soil variables were significant in all models, with $\mathrm{pH}$ and percent sand appearing in the all-Salix models and soil electrical conductivity appearing in the S. exigua models. Higher percent sand was associated with larger increases in all-Salix cover, while higher $\mathrm{pH}$ and electrical conductivity were associated with decreases in all-Salix cover.

S. exigua change in cover decreased with increasing initial S. exigua cover. Remaining significant variables were climate conditions, generally showing that higher precipitation and lower temperature were associated with increases in Salix cover. Results of univariate models on variables found to be significant in the mixed models are shown in Appendices D-E.

\section{Question 2b: What growing conditions explain final Salix cover?}

Stepwise selection on final-year cover of all-Salix species resulted in 9 distinct final models, with adjusted $\mathrm{R}^{2}$ values ranging from roughly 0.30 to 0.45 (Fig. $5 \mathrm{~A}$ ). Stepwise selection on $S$. exigua cover resulted in 4 distinct models, with similar adjusted $\mathrm{R}^{2}$ values ranging from roughly 0.51 to 0.54 (Fig. 5B). Site type and soil percent sand were significant in all models; site type was driven by desirable reference sites being distinct from all restored and undesirable reference sites. Soil $\mathrm{pH}$ and climate variables (precipitation and temperature) were also commonly selected as significant across all-Salix and S. exigua-only models. Otherwise, all-Salix and $S$. exigua-only models were relatively distinct from each other; distance to water and Tamarix cover were significant across the all-Salix models but appeared rarely or not at all in $S$. exigua models. Likewise, active plant introduction, soil electrical conductivity, and herbicide use were consistently significant predictors of $S$. exigua cover but not all-Salix cover. Active seeding had a positive effect on final $S$. exigua cover while active planting had a negative effect. Soil characteristics were found to be consistent predictors of $S$. exigua cover, specifically soil pH and soil electrical conductivity, which both had negative relationships with $S$. exigua cover. In addition, precipitation during the year of sampling was found to have a positive relationship with $S$. exigua cover in 3 of the 4 models. In the all-Salix models, all observed relationships were negative aside from precipitation during the sampling year. Results of univariate models on variables found to be significant in the mixed models are shown in Appendices F-H.

\section{Discussion}

\section{How does Salix respond to reduction in Tamarix cover and does Salix growth compensate for losses in potential SWFL nesting habitat following Tamarix removal?}

Our findings suggest that removal of invasive Tamarix trees can lead to an increase in native Salix, but only when there is enough moisture to support such a hydrophilic genus (Fig. 6A). The model with interactions between change in Tamarix cover and two of the hydrology variables explained a surprisingly high degree of variability in Salix change over time (approximately a third). We also found evidence that cut-stump treatments are most effective at promoting replacement of Tamarix by Salix. However, given that removal method alone was not a strong predictor of Salix change over time, and the sample sizes of 
other types of removal were likely too low to adequately test them individually, this particular result should be treated with caution.

Importantly, the slope of the relationship between change over time in these two genera indicates that overall, less Salix is gained than Tamarix lost for a given amount of reduction in cover, regardless of either water availability or removal method. It is possible that there was insufficient time for Salix to regenerate once the Tamarix was removed; Salix exigua reaches maturity in 1-2 years (Ottenbreit and Staniforth 2011), and several sites were known to have been measured less than 2 years following restoration. More likely, however, is that this lack of full replacement reflects of the fact that Salix spp, and particularly $S$. exigua, tends to grow in narrow bands along the river's edge, whereas Tamarix can fill the entire floodplain (González et al 2020; Fig. 6B). That is, the novel habitat of Tamarix thickets may provide much more potential nesting area than the Salix it replaced.

Thus, in terms of SWFL conservation, our study is the first to demonstrate across a range of environmental conditions and large geographic area that Tamarix removal projects in the American Southwest are likely to reduce potential SWFL habitat. This is consistent with the consensus that Tamarix biocontrol specifically has had negative impacts on existing SWFL habitat (Dudley and Bean 2012; Bean and Dudley 2018), as well as findings of previous, smaller-scale studies on bird response to Tamarix removal in general (Raynor et al. 2017). However, one should not take this to mean that all Tamarix removal would be bad for SWFL; not all Tamarix stands constitute suitable habitat, either in terms of branching morphology (Goetz, unpublished research) or availability of water. The SWFL requires close proximity to standing water for insect foraging (Hatten 2016) while Tamarix often grows far from perennial water (Cleverly 2013). Therefore, many of the Tamarix removal sites in this study would not have made good SWFL habitat, even in the unlikely event that Salix was able to grow there.

These results indicate that while Tamarix removal does promote Salix regeneration to some degree, the two species can also increase or decrease in cover for other reasons unrelated to interspecific interactions (González et al. 2020), and that in general Salix recovery should not be expected to fully replace Tamarix losses.

\section{Under what conditions do we see the most growth of Salix over time?}

In general, we found that Salix responded favorably to a cooler and wetter climate with low $\mathrm{pH}$, with $S$. exigua particularly favoring non-saline soils and total Salix favoring sandier soils. This is consistent with previous literature on the environmental conditions favorable for Salix growth (Rood et al. 2011; Merritt and Shafroth 2012; Ohrtman et al. 2012; Stromberg and Merritt 2016). We also found that Salix cover change over time was higher in sites further from paved roads and railways, suggesting an effect of human development. This is likely confounded by the fact that restoration sites in general need to be accessible by vehicles (on average, reference sites were further from roads than restoration sites in our dataset), but is still consistent with other findings that proximity to roads and other anthropogenic features is a strong predictor of ecological degradation (Trombulak and Frissell 2000; Chazdon 2017); proximity to roads also indicates increased urban land use nearby. 
While interspecific competition with Tamarix only seemed to be playing a role in wetter sites, intraspecific competition appeared to be less conditional, as we found an overall negative relationship between $S$. exigua initial cover and change over time. Since $S$. exigua is an early seral species which can reproduce vegetatively (Douhovnikoff et al. 2005; Rood et al. 2011), it makes sense that it could be a strong competitor over a short time, preventing new individuals of the same species from establishing and propagating within the narrow region it occupies along rivers and streams.

The only management variables that were associated with better Salix cover outcomes were the use of herbicide and active plant introduction. Our findings suggest that herbicide is effective at reducing growth potential of both Tamarix and secondary invaders that may inhibit Salix growth, particularly under relatively wetter conditions. Sites where planting occurred had lower final cover of $S$. exigua while sites where seeding occurred had higher cover. This is likely explained by the fact that we only had data on whether any active planting was conducted, not the species used. If plants from genera other than Salix were used, we would expect to see lower Salix cover due to competition. It is also not uncommon for Salix plantings to fail, particularly when a site is not wet enough (González et al. 2018). Seeding of riparian species is more commonly used in sites that have access to water, thus this positive relationship with Salix growth is likely due to this confounding effect, rather than any positive effect of seeding, as Salix is rarely restored with artificial seeding (Sher et al. 2010; González et al. 2018), due to their low longevity (Grabau et al. 2011).

\section{What conditions are associated with the greatest cover of Salix?}

In contrast with the lack of importance of Tamarix for explaining change in Salix over time, the abundance of Tamarix was in every model to explain final cover of the composite of all Salix species. Considered alone, this could have suggested Tamarix consistently competitively excluding Salix. However, given the previous findings that demonstrate the conditional role of Tamarix as revealed by changes over time, the negative correlation between the two genera at a single point in time is further evidence of their differences in niche. In most cases, the same conditions that were associated with a positive change over time also predicted final cover, namely those associated with lower drought stress and sandy soils. Riparian areas of the Southwest have undergone hydrologic changes due to altered and regulated flooding regimes, so many historic wetland sites have transitioned to assemblages more characteristic of upland areas (Auerbach et al. 2013; Bay 2013). Sandier soils and low salinity can be indicative of more common flooding, which is favorable for Salix growth (Ohrtman et al. 2012; Meinhardt and Gehring 2013). In contrast, Tamarix is known to have a higher tolerance to salinity, higher temperatures and drought conditions than Salix and other native tree species (Merritt and Shafroth 2012; Ohrtman et al. 2012; Ohrtman and Lair 2013). Thus, many of the Tamarix-dominated sites will not be ecologically favorable for Salix regeneration following removal.

Further, Tamarix can exacerbate the conditions that are unfavorable to Salix, by increasing soil and groundwater salinity (Nagler et al. 2008, Ohrtman and Lair 2013) as well as both frequency and temperature of fires (Drus 2013). The importance of soil salinity in predicting S. exigua cover in our study 
underlines the importance of this potential impact of Tamarix. Because salts left by Tamarix remain after removal unless there is flooding to remove it (Ohrtman et al. 2012), there is the potential of a legacy effect of Tamarix invasion, distinct from a pre-existing separate environmental niche, which will prevent S. exigua establishment.

\section{Conclusion}

Our analysis of data from 392 sites across the American Southwest suggests that removal of invasive Tamarix can increase cover of Salix but only in hydrologically favorable sites, and that Salix did not fully replace lost Tamarix cover. This has important implications for keeping SWFL habitat levels stable following removal. The failure of Salix to fully fill the released space is in part because these genera occupy different niches-differences Tamarix is capable of exacerbating, even after removal, Therefore, we suggest that management should focus on sites with lower overall climatic stress if the goal is to increase Salix cover. Furthermore, if future SWFL habitat is the only management goal in a particular site, and other requirements for that species are met, it may be more beneficial to leave Tamarix in place. Our results broadly demonstrate that when an invasive species provides similar ecosystem benefits as a native species, understanding and planning around local environmental conditions is highly important for achieving outcomes that retain the benefits, which will be lost if the invader is not replaced by the native competitor. These results speak to the larger reality that biological invasions are merely one facet of ecological degradation, and that underlying conditions may continue to prevent ecosystem recovery even in the absence of the initial invader.

\section{Declarations}

Funding: This project used data funded by the National Science Foundation (project \# 1617463), a Marie Curie International Outgoing Fellowship (ESSFORES project \# 299044), and a University of Denver undergraduate research grant.

Conflicts of interest: The authors declare no conflict of interests.

Availability of data and material: Entire dataset is not available, but project uses data deposited in a Dryad digital repository https://doi.org/10.5061/dryad.70mt1

Code availability: Not applicable.

Author contributions: AAS and IM conceived of the study and IM conducted initial data analysis. AG and IM conducted final data analyses with support from AAS, and AG led the writing effort with extensive assistance from AAS.

Ethics approval: Not applicable.

Consent to participate: Not applicable. 
Consent for publication: Not applicable.

\section{Acknowledgements}

This project used data funded by the National Science Foundation (project \# 1617463) and a Marie Curie International Outgoing Fellowship (ESSFORES project \# 299044), as well as a University of Denver (DU) undergraduate research grant. The authors would like to thank Eduardo González, Shannon Murphy and the rest of the DU Ecology and Evolutionary Biology group for their feedback on the manuscript, as well as Patrick Shafroth for suggestions when formulating the project.

\section{References}

1. Auerbach DA, Merritt DM, Shafroth PB (2013) Tamarix, Hydrology, and Fluvial Geomorphology. In: Sher AA, Quigley MF (eds) Tamarix. a case study of ecological change in the American West. Oxford University Press, New York, pp 99-122

2. Bay RF (2013) Revegetation after Tamarisk Removal: What Grows Next? In: Sher AA, Quigley MF (eds) Tamarix. a case study of ecological change in the American West. Oxford University Press, New York, pp 426-440

3. Bean DW, Dudley TL (2018) A synoptic review of Tamarix biocontrol in North America: tracking success in the midst of controversy. BioControl 63:1-16. https://doi.org/10.1007/s10526-018-9880$\mathrm{x}$

4. Ceia RS, Sampaio HL, Parejo SH, et al (2011) Throwing the baby out with the bathwater: Does laurel forest restoration remove a critical winter food supply for the critically endangered Azores bullfinch? Biol Invasions 13:93-104. https://doi.org/10.1007/s10530-010-9792-x

5. Cleverly JR (2013) Water Use by Tamarix. In: Sher AA, Quigley MF (eds) Tamarix. a case study of ecological change in the American West. Oxford University Press, New York, pp 85-98

6. Dudley TL, Bean DW (2012) Tamarisk biocontrol, endangered species risk and resolution of conflict through riparian restoration. BioControl (Heidelberg) 57:331-347.

https://doi.org/http://dx.doi.org/10.1007/s10526-011-9436-9

7. Dueñas MA, Ruffhead HJ, Wakefield NH, et al (2018) The role played by invasive species in interactions with endangered and threatened species in the United States: a systematic review. Biodivers Conserv 27:3171-3183. https://doi.org/10.1007/s10531-018-1595-x

8. Essl F, Hulme PE, Jeschke JM, et al (2017) Scientific and normative foundations for the valuation of alien-species impacts: Thirteen core principles. Bioscience 67:166-178. https://doi.org/10.1093/biosci/biw160

9. González E, Shafroth PB, Lee SR, et al (2020) Riparian Plant Communities Remain Stable in Response to a Second Cycle of Tamarix Biocontrol Defoliation. 1863-1875

10. González E, Sher AA, Anderson RM, et al (2017) Vegetation response to invasive Tamarix control in southwestern U.S. rivers: a collaborative study including 416 sites. Ecol Appl 27:1789-1804. 
https://doi.org/10.1002/eap.1566

11. González E, Sher AA, Tabacchi E, et al (2015) Restoration of riparian vegetation: A global review of implementation and evaluation approaches in the international, peer-reviewed literature. J Environ Manage 158:85-94. https://doi.org/10.1016/j.jenvman.2015.04.033

12. Grabau MR, Milczarek MA, Karpiscak MM, et al (2011) Direct seeding for riparian tree re-vegetation: Small-scale field study of seeding methods and irrigation techniques. Ecol Eng 37:864-872. https://doi.org/10.1016/j.ecoleng.2011.01.003

13. Hatten JR (2016) A satellite model of Southwestern Willow Flycatcher (Empidonax traillii extimus) breeding habitat and a simulation of potential effects of tamarisk leaf beetles (Diohabda spp.)

14. Hultine KR, Dudley TL (2013) Tamarix from Organism to Landscape. In: Sher AA, Quigley MF (eds) Tamarix. a case study of ecological change in the American West. Oxford University Press, New York, pp 149-167

15. Kettenring KM, Adams CR (2011) Lessons learned from invasive plant control experiments: A systematic review and meta-analysis. J. Appl. Ecol. 48:970-979

16. Ma Z, Gan X, Choi CY, Li B (2014) Effects of invasive cordgrass on presence of marsh grassbird in an area where it is not native. Conserv Biol 28:150-158. https://doi.org/10.1111/cobi.12172

17. Meinhardt KA, Gehring CA (2013) Tamarix and Soil Ecology. In: Sher AA, Quigley MF (eds) Tamarix. a case study of ecological change in the American West. Oxford University Press, New York, pp 225239

18. Merritt DM, Shafroth PB (2012) Edaphic, salinity, and stand structural trends in chronosequences of native and non-native dominated riparian forests along the Colorado River, USA. Biol Invasions 14:2665-2685. https://doi.org/10.1007/s10530-012-0263-4

19. Monaco TA, Mangold JM, Mealor BA, et al (2017) Downy Brome Control and Impacts on Perennial Grass Abundance: A Systematic Review Spanning 64 Years. Rangel Ecol Manag 70:396-404. https://doi.org/10.1016/j.rama.2016.09.008

20. Moyka PJ (2016) NON-NATIVE TREES PROVIDE HABITAT FOR NATIVE HAWAIIAN FOREST BIRDS. 2016

21. Nagler PL, Glenn EP (2013) Tamarisk: Ecohydrology of a Successful Plant. In: Sher AA, Quigley MF (eds) Tamarix. a case study of ecological change in the American West. New York, pp 63-85

22. Ohrtman MK, Lair KD (2013) Tamarix and Salinity: An Overview. In: Sher AA, Quigley MF (eds) Tamarix. a case study of ecological change in the American West. Oxford University Press, New York, pp 123-148

23. Ohrtman MK, Sher AA, Lair KD (2012) Quantifying soil salinity in areas invaded by Tamarix spp. J Arid Environ 85:114-121. https://doi.org/10.1016/j.jaridenv.2012.04.011

24. Packer JG, Delean S, Kueffer C, et al (2016) Native faunal communities depend on habitat from nonnative plants in novel but not in natural ecosystems. Biodivers Conserv 25:503-523. https://doi.org/10.1007/s10531-016-1059-0 
25. Pinheiro J, Bates D, R Core Team (2020) nlme: Linear and Nonlinear Mixed Effects Models

26. Raynor EJ, Cable TT, Sandercock BK (2017) Effects of Tamarix removal on the community dynamics of riparian birds in a semiarid grassland. Restor Ecol 25:778-787. https://doi.org/10.1111/rec.12497

27. Rodríguez B, Siverio F, Siverio M, et al (2015) Nectar and pollen of the invasive century plant Agave americana as a food resource for endemic birds. Bird Study 62:232-242.

https://doi.org/10.1080/00063657.2015.1015484

28. Rodriguez LF (2006) Can invasive species facilitate native species? Evidence of how, when, and why these impacts occur. Biol Invasions 8:927-939. https://doi.org/10.1007/s10530-005-5103-3

29. Rood SB, Goater LA, Gill KM, Braatne JH (2011) Sand and sandbar willow: A feedback loop amplifies environmental sensitivity at the riparian interface. Oecologia 165:31-40. https://doi.org/10.1007/s00442-010-1758-2

30. Shafroth PB, Cleverly JR, Dudley TL, et al (2005) Control of Tamarix in the Western United States: Implications for Water Salvage, Wildlife Use, and Riparian Restoration. Environ Manage 35:231-246. https://doi.org/http://dx.doi.org/10.1007/s00267-004-0099-5

31. Sher A, Quigley MF (2013) Tamarix: a case study of ecological change in the American West. New York: Oxford University Press, New York

32. Sher AA, El Waer H, González E, et al (2018) Native species recovery after reduction of an invasive tree by biological control with and without active removal. Ecol Eng 111:167-175. https://doi.org/10.1016/j.ecoleng.2017.11.018

33. Spence AR, Tingley MW (2020) The challenge of novel abiotic conditions for species undergoing climate-induced range shifts. Ecography (Cop) 43:1571-1590. https://doi.org/10.1111/ecog.05170

34. Van Riel P, Jordaens K (2000) Eradication of exotic species. Trends Ecol Evol 15:515-516. https://doi.org/10.1016/s0169-5347(00)02006-1

35. Vitousek PM, D'Antonio CM, Loope LL, Westbrooks R (1996) Our mobile society is redistributing the species on the earth at a pace that challenges ecosystems I threatens human health and strains economies. Am Sci 84:468-477

36. Vitousek PM, Mooney HA, Lubchenco J, Melillo JM (2008) Human domination of Earth's ecosystems. Urban Ecol An Int Perspect Interact Between Humans Nat 277:3-13. https://doi.org/10.1007/978-0387-73412-5_1

37. Zavaleta ES, Hobbs RJ, Mooney HA (2001) Viewing invasive species removal in a whole-ecosystem context. Trends Ecol Evol 16:454-459. https://doi.org/10.1016/S0169-5347(01)02194-2

38. Zuur AF, leno EN, Walker NJ, et al (2009) Mixed Effects Models and Extensions in Ecology with R. Springer, New York

\section{Figures}




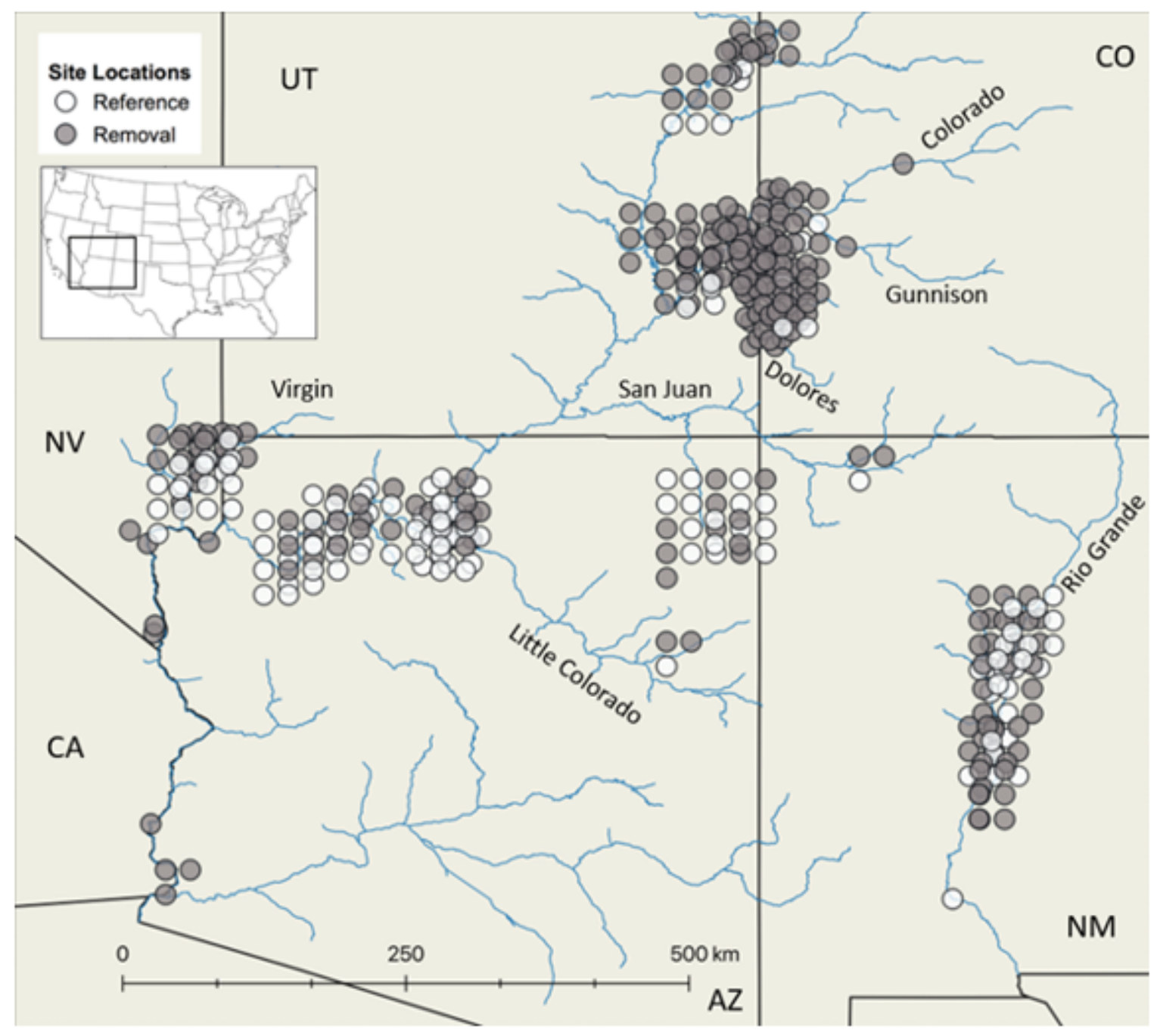

Figure 1

Map showing study sites across the American Southwest. Dark circles represent removal sites and white circles represent desirable and undesirable reference sites. All sites are within $1.4 \mathrm{~km}$ of the riverbank with which they are associated. Site locations are formatted to as to show number of sites along a certain stretch of the river and as such the figure does not show exact locations of each particular site. 


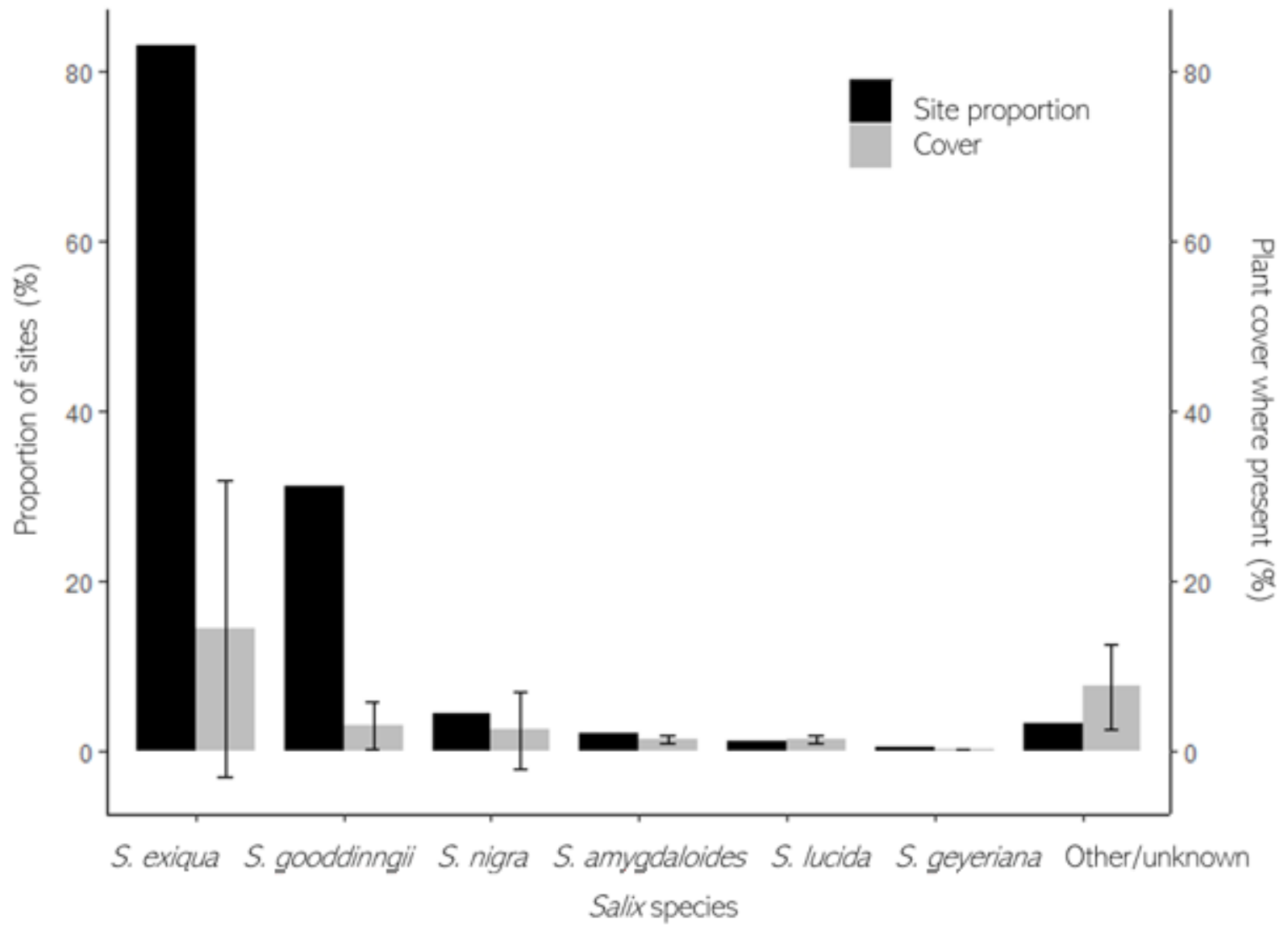

Figure 2

Summary of species in the genus Salix recorded at study sites, showing proportion of sites where each species was found (black) as well as mean and $+/-1$ standard deviation of each species' cover at sites where it was recorded (grey). 


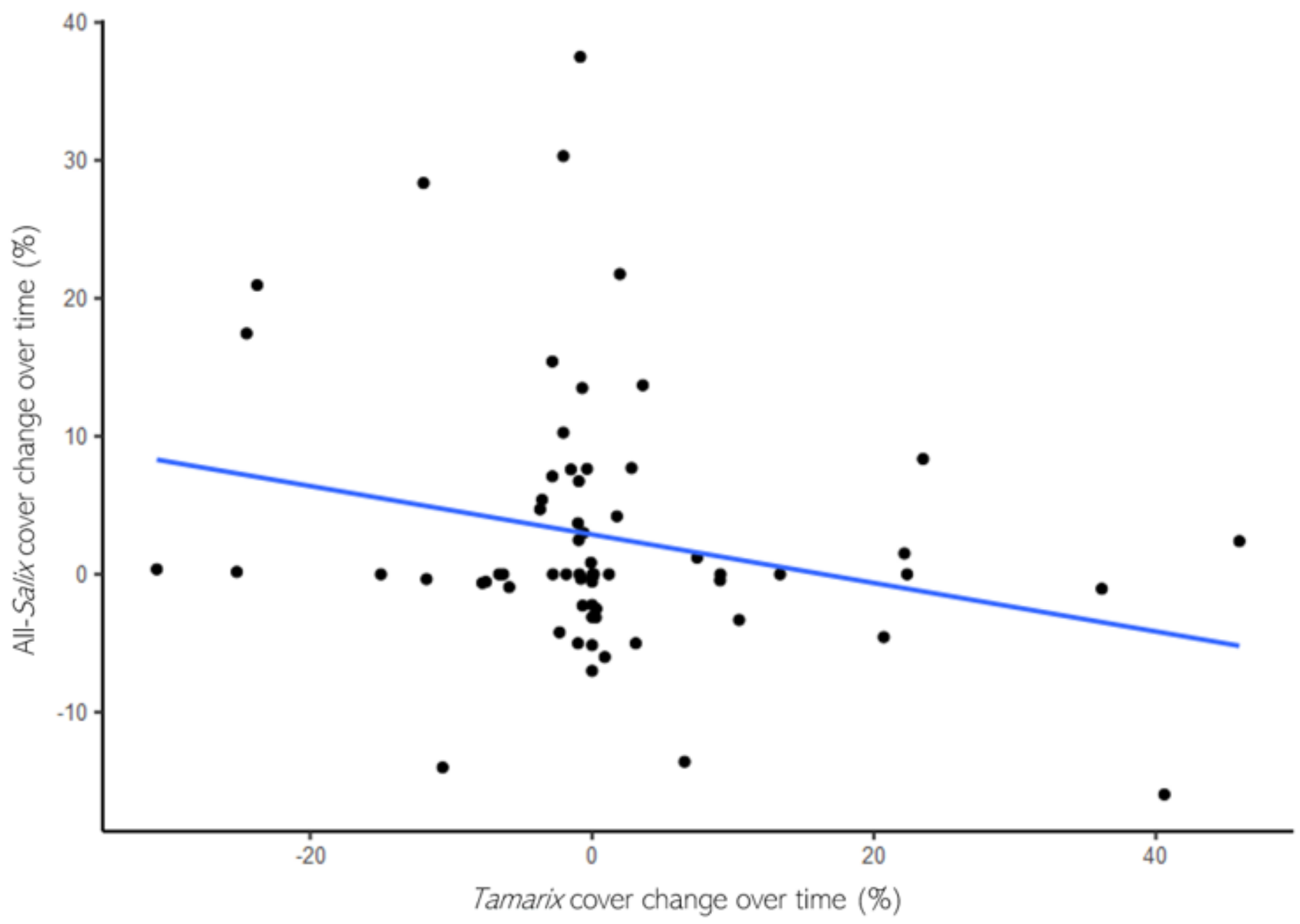

\section{Figure 3}

Change in all-Salix percent cover compared with change in Tamarix percent cover over time, in sites where cut-stump treatment was used. Blue line is a trendline calculated using a mixed model with river reach as a random factor. Adjusted marginal $\mathrm{R} 2=0.058, \mathrm{p}<0.05$. 
a

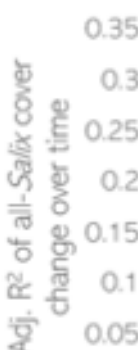

0.3

0.25

0.2

0.15

0.1

0

SIGNIFICANT VARIABLES

\begin{tabular}{llllll}
\hline Any herbicide used: "yes" & 0.602 & 0.904 & 0.773 & 1.273 & 1.395 \\
\hline Soil percent sand & 1.510 & 1.456 & 1.546 & 1.384 & 1.388 \\
Distance to nearest paved road or railway & 3.015 & 2.725 & 2.875 & 2.257 & \\
Distance to water & 1.332 & & & & \\
Soil pH & -1.759 & -1.322 & -1.430 & -2.677 \\
Minimum normal temperature & & & & & \\
Maximum normal temperature & 2.349 & -2.628 & & \\
$\quad$ & & 2.651 &
\end{tabular}

b
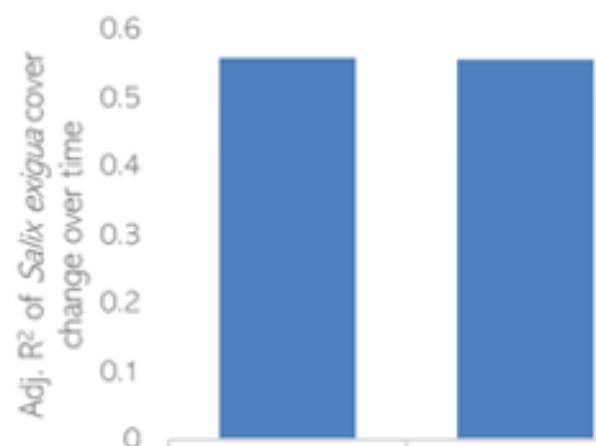

2

Site type
2.762

Any herbicide used: "yes"

Soil electrical conductivity

$-1.684$

$-7.088$

Salix exigua cover before treatment

Normal precipitation

Minimum temperature year sampling

Minimum normal temperature

\section{SIGNIFICANT VARIABLES}

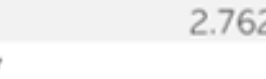

$-6.927$

2.240
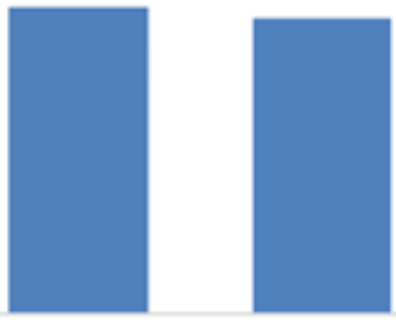

4

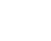
2

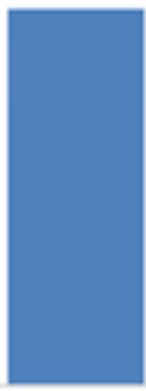

3

2.993

$-1.814$

$-1.824$

$-6.926$

$-6.753$

$-7.002$

$-2.097$

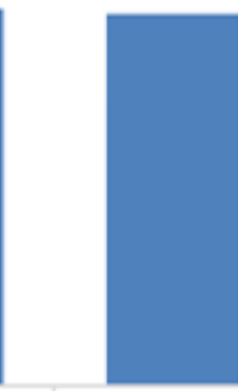

4

2.957

3.016 
but in many cases the "unknown" category had a higher slope coefficient. For all models, $p<0.0001$; further details reported in Appendix B.

a

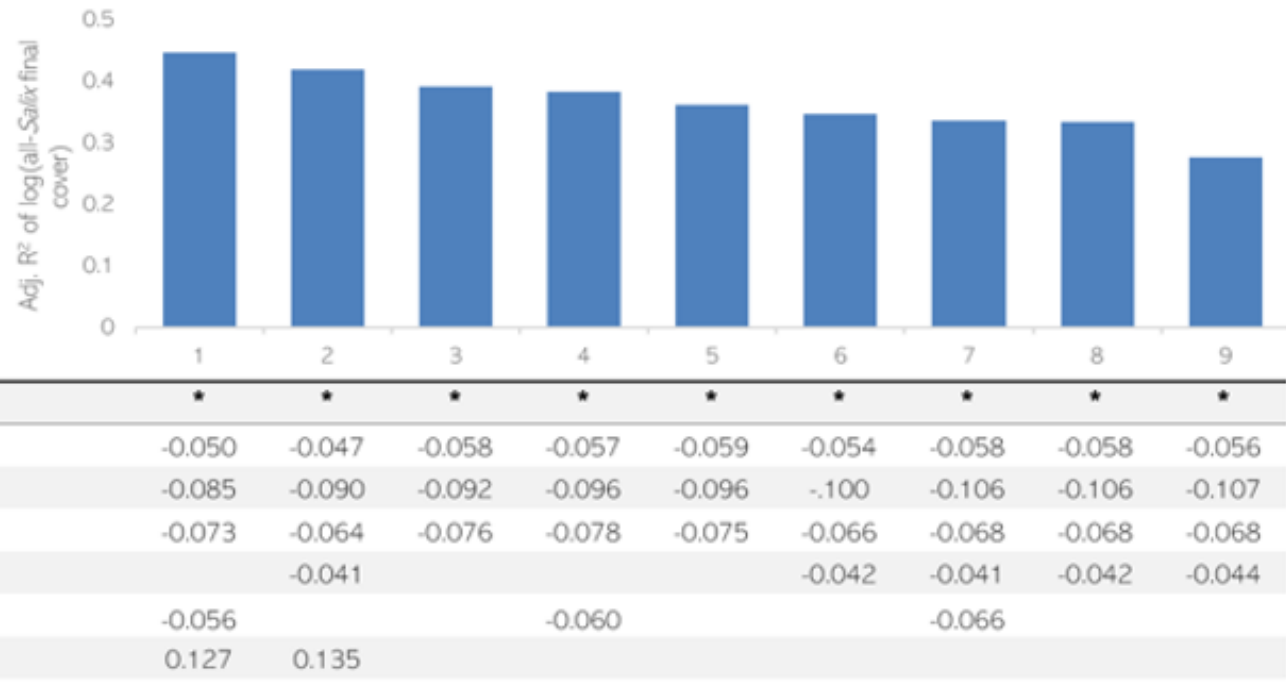

\section{SIGNIFICANT VARLABLES}

\section{Site type}

Distance to water

Percent cover Tamarix

Soil percent sand

Soil pH

Distance to nearest paved road

Precipitation year sampling

Normal precipitation

Minimum temp year sampling

Minimum normal temp

Maximum temp year sampling

Distance to nearest road

0.101

$-0.067$

$-0.089$

$-0.074$

$-0.056$

b

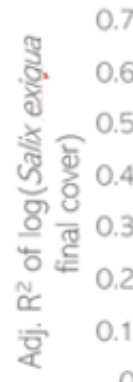

0.7

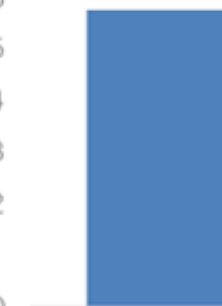

1

2
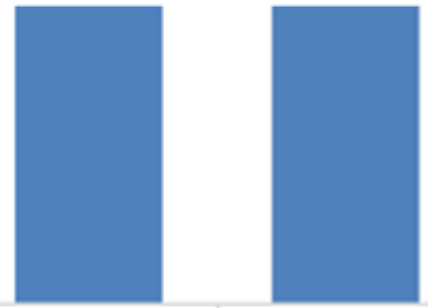

3

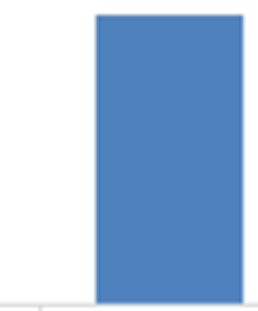

4

SIGNIFICANT VARIABLES

Site type

Active plant introduction

Any herbicide used: "yes"

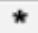

Soil percent sand

0.361

0.358

0.408

0.449

Soil pH

$-0.178$

$-0.234$

$-0.234$

$-0.246$

Soil electrical conductivity

$-0.275$

$-0.165$

$-0.162$

$-0.183$

Precipitation year sampling

0.289

$-0.262$

$-0.268$

$-0.297$

Distance to water

0.284

0.199

Distance to nearest paved road or railway

$-0.141$

$-0.174$

0.154

Longitudinal slope

0.167

\section{Figure 5}

Summary of linear mixed models from stepwise selection to explain (A) final-year cover of all Salix and (B) final-year S. exigua cover as determined based on AIC. Each bar represents adjusted R2 of a model. Table shows slope coefficients for significant variables in each model; for site type, asterisks are shown 
to denote significance as there were six different site types. ; for site type and active plant introduction, asterisks are shown to denote significance as there were six different site types, and for active plant introduction there were four categories. For herbicide use, slope is shown for the "yes" category, but in many cases the "unknown" category had a higher slope coefficient. For all models, $p<.0001$; further details reported in Appendix B.
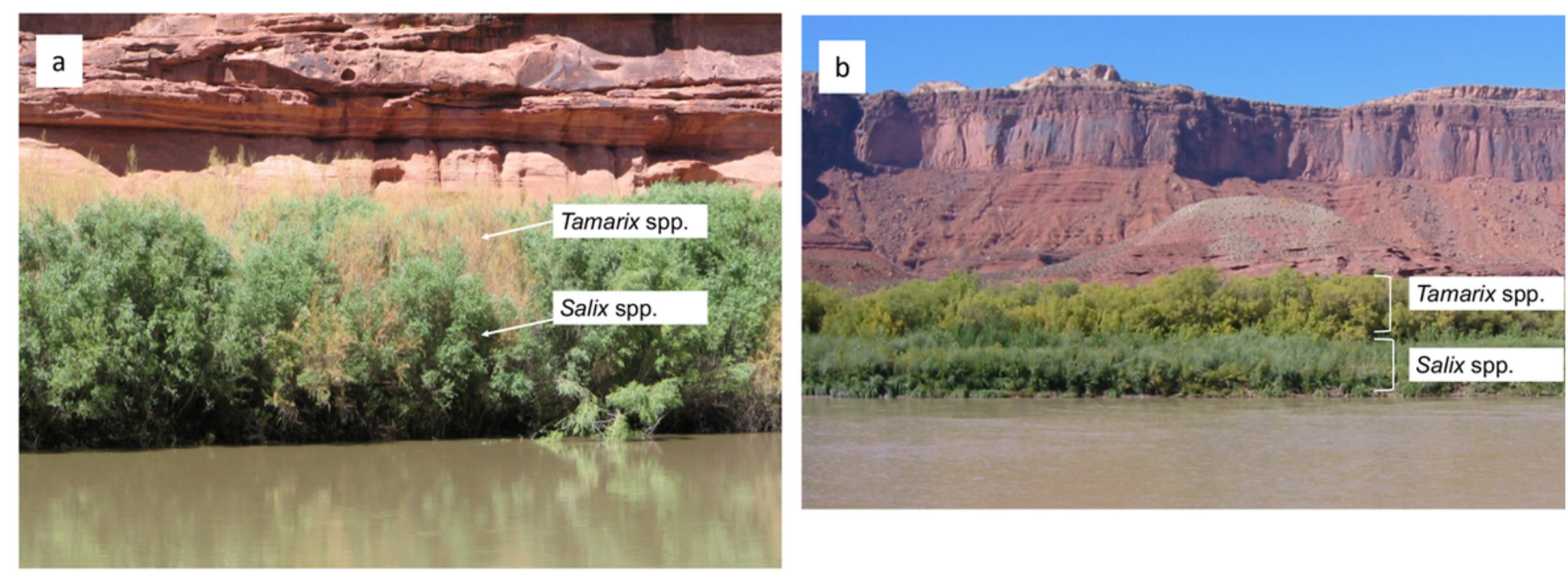

\section{Figure 6}

Two areas where both Tamarix and Salix occur, near Moab, Utah. A) Here we can see an illustration of Salix being competitively released by reduction in cover of Tamarix (in this case by defoliation by the biocontrol beetle); Salix is literally growing up through the bare branches of Tamarix. B) Salix typically grows in the wettest part of the floodplain, directly adjacent to the river, with Tamarix occupying a much broader niche. The latter can be seen behind the fringe of Salix in the front. Removing the Tamarix in the back may or may not result in an expansion of Salix.

\section{Supplementary Files}

This is a list of supplementary files associated with this preprint. Click to download.

- Appendix.docx 